\title{
$5.5 \mathrm{cal} \mathrm{ka} \mathrm{BP}$ 气候事件、人口增长、条件限制与 中国史前复杂社会产生
}

\author{
吴文祥 ${ }^{*}$, 郑洪波 ${ }^{2}$, 侯梅 ${ }^{1,3}$, 葛全胜 $^{1 \dagger}$
}

1. 中国科学院地理科学与资源研究所, 中国科学院陆地表层格局与模拟重点实验室, 北京 100101 ;

2. 云南大学地球系统科学研究中心, 昆明 650091 ;

3. 中国科学院大学, 北京 100049

* 通讯作者, E-mail: wuwx@igsnrr.ac.cn

†通讯作者, E-mail: geqs@igsnrr.ac.cn

收稿日期: 2017-06-01; 接受日期: 2017-12-04; 网络版发表日期: 2017-12-20

国家自然科学基金项目(批准号: 41672176)和国家重点基础研究发展计划项目(编号: 2015CB953802)资助

摘要 复杂社会的产生是人类社会发展史上一个重要里程碑. 中国是世界上最早出现复杂社会的地区之一, 然而 其产生动因一直悬而未决. 本文基于目前考古和全新世气候变化证据, 结合人口学理论, 从能动性理论的视角, 对 中国 $5.5 \mathrm{cal} \mathrm{ka} \mathrm{BP}$ 左右多个地区同时出现复杂社会的动因进行了解释. 认为气候变化、人口增长、条件限制三个 因素共同作用，引起人口-资源失衡，触发人群间的冲突和竞争，为一些热衷权力的能动者提供了机会，使他们能 够突破平等化机制的限制, 成为集中决策的领导者, 进而导致大规模的复杂社会的初现. 降温期间极端气候事件 的增加引起人口-资源压力经常性发生，触发不同社会团体之间竞争和战争的频率增加，为集中领导权的合法 化、制度化和持久性创造了条件, 并最终促使制度化不平等社会的产生. 研究结果不仅能够很好解释中国复杂社 会产生的过程和动因, 而且能够解释目前其他理论不能给出合理解释的两种现象: 即中国最早的复杂社会为何产 生于5.5cal ka BP左右而不是其他时间，为何在多地区同时出现.

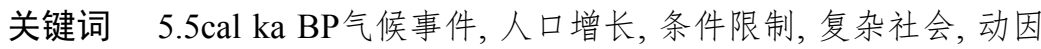

\section{1 引言}

“复杂社会”(complex society)或“社会复杂化”(Social complexity)是指社会从简单到复杂的变化过程以 及社会发展到某种程度的特定状态. “复杂化”可以分 解为“异质性”(heterogeneity)和“不平等”(inequality)两 个概念, 前者是指社会群体之间人口的构成, 后者是指
一个社会内部获取原料和社会资源的不同途径 (McGuire, 1983). 本文所讨论复杂社会主要指制度化 社会不平等社会(Institutionalized social inequality) (Mattison等, 2016), 而制度化领导者的出现被认为是 不平等社会或复杂社会产生的关键(Vaughn等, 2009).

研究表明，至少在 10 万年前现代人出现以后 (Boehm，1999), 甚至200多万年前(Hayden, 2001), 人 
类一直以游群或部落的方式生活在一种平等社会中. 这种状况一直持续到全新世中期, 即大约 $5.5 \mathrm{cal} \mathrm{ka} \mathrm{BP}$ (cal ka BP指距今千年)前后发生了革命性的转变. 该时 期全球多个地区近乎同时地出现了明显的社会复杂化 现象(Sandweiss等, 1999; Brooks, 2006), 标志着人类从 平等社会演进至不平等社会. 这一事件被公认为人类 社会演进历史上的一个重要里程碑, 较近, 考古学界 将复杂社会产生的原因列为未来 25 年考古学研究的 5 大挑战科学问题之一(Kintigh等, 2014).

中国是世界上少数最早出现复杂社会的地区之 一. 大量考古证据表明, $5.5 \mathrm{cal} \mathrm{ka} \mathrm{BP}$ 前后, 中国多个地 区几乎同时出现了明显的社会复杂化现象(陈淳, 2003; Liu和Chen, 2012; 橸丰实, 2012), 中国古文明开 始起源(严文明, 1999; 栾丰实, 2012; 陈淳, 2003), 并奠 定了夏商周三代文明社会进一步发展的基础(严文明, 1999).

然而，对于中国这次里程碑式的人类社会演进事 件形成的动因一直存在较大争议(陈淳, 2003; Liu和 Chen, 2012). 近年来, 随着测年精确、分辨率高的古 气候记录的增加, 以及考古文化绝对年代序列的准确 厘定, 研究者发现 $5.5 \mathrm{cal} \mathrm{ka} \mathrm{BP}$ 气候转变与这一时期全 球多个地区(Kennett和Kennet, 2006; Küper和Kröpelin, 2006), 包括中国地区(Sandweiss等, 1999; 吴文祥和刘 东生, 2002; Brooks, 2006)在内首次出现复杂社会现象 在发生时间上的一致性，并从气候变化影响与适应的 角度证明二者之间可能存在因果关系. 然而，这类气 候变化适应论假说受到多方面质疑. 一是该理论仅仅 考虑气候变化的影响, 而未考虑其他因素尤其是人口 增长的作用, 同时以群体为研究对象(Collectivism), 将 人群视为千人一面的被动应对者，从而陷入了环境决 定论的泥潭; 另一方面, 这类假说假定了群体内部的 人际间不平等现象已经产生, 因此实际上未能解释最 初复杂社会产生的动因(Wiessner，2002；Kantner， 2009).

能动性(Agency)理论认为人类本身才是人类社会 演进主要的驱动力 (Vaughn等, 2009). 该理论以个体为 研究对象, 认为人群中存在一些自我提升者 (self-aggrandizer)(Clark和Blake，1994)或自我敛聚者(self-accumulator)(Hayden，1995)，他们在人类本身所固有自 私利益驱动下, 对声望、财富和地位追求所付出的行 动, 是社会演进的主要驱动力(Wiessner, 2002; Kantner,
2009). 能动性理论有助于解释最初的社会复杂化的产 生. 然而, 该理论往往忽略社会结构和自然因素对个人 能动性的限制作用，将平等社会视为一种结构约束力 较弱的简单社会, 人类可以随意发挥其能动性, 并导 致社会的演进(Wiessner, 2002; Kantner, 2009). 但是平 等社会至少成功运行了 10 多万年, 结构极为复杂, 个人 的能动性很难轻易突破这种结构的限制 (Boehm, 1999), 因此需要了解为能动者提供发挥能动性机会的 外部条件(Kantner, 2009).

本文首先总结和分析了中国 $5.5 \mathrm{cal} \mathrm{ka} \mathrm{BP}$ 左右社会 复杂化以及人群间冲突和战争的考古证据，支持了人 群间冲突和战争是社会演进的主要驱动力的理论; 然 后基于全新世古气候记录, 识别出 $5.5 \mathrm{cal} \mathrm{ka} \mathrm{BP}$ 气候事 件; 最后结合人口学理论, 从能动性理论的角度, 尝试 对中国复杂社会产生的过程和动因等提出另一种 解释.

\section{5.5cal ka BP左右多地区复杂社会的产生}

大量考古证据表明, 在 $5.5 \mathrm{cal} \mathrm{ka} \mathrm{BP}$ 前后, 中国多个 地区考古学文化近乎同时地产生了重要的转变. 表现 为先前平等社会转变成制度化不平等社会，出现了明 显的社会复杂化现象.

在渭河中上游，甘肃秦安大地湾遗址在大约仰韶 文化中晚期(5.8 4.9cal ka BP), 出现了三级区域聚落. 其中最大的房屋(F901)占地面积达 $290 \mathrm{~m}^{2}$, 或为宫殿式 大型建筑(严文明, 1999; Liu, 2005), 其前还存在面积约 $1000 \mathrm{~m}^{2}$ 的大型公共广场. 该聚落被认为是整个区域聚 落等级体系中的中心性高等级聚落(Liu和Chen, 2012). 它的出现反映出聚落间的分化, 社会复杂性较前期的 平等社会明显增强.

在豫西灵宝地区, 仰韶文化中期, 即约 5.3 cal ka BP 左右出现了明显的社会复杂化现象，表现在三个方面: 一是在区域聚落遗址面积和空间分布上，表现出明显 的分级分层现象, 如最大的北阳平遗址面积近 100 万 平方米; 二是在聚落内部也产生了分化, 出现了特大 型房址, 如F105室内面积约 $200 \mathrm{~m}^{2}$; 三是西坡墓地 34 座 墓葬等级差别明显(橸丰实, 2012; 李新伟, 2016). 尤其 值得注意的是，考古证据还可能显示出等级的世袭现 象，如西坡村一个大型墓葬中，一位年仅 4 岁的墓主人 却随葬3 件玉钱(王震中, 2014). 因为小孩不可能取得 
拥有这些物品的权力，因此一般被认为是从等级的世 袭所得(Marcus, 2008).

在河南郑州西山，仰韶晚期(5.3 4.8cal ka BP)(杨 肇清, 1997)出现了土城. 其面积为25公顷. 夯土城墙聚 落的出现表明技术、社会组织和领导能力都达到了相 当的程度, 被认为是社会复杂化出现的一个重要标志 (Liu, 2005). 另外，出土的人骨显示当时可能出现了人 殉(杨肇清, 1997; Liu, 2005).

在黄河下游, 在大汶口文化中期, 即大约 $5.5 \mathrm{cal} \mathrm{ka}$ $\mathrm{BP}$ 左右, 海岱地区史前社会开始了社会复杂化进程, 主要表现四个方面:（1）野外遗址普查揭示出至少两 级聚落分层现象不止在山东一个地区出现, 如山东中 部地区，大汶口晚期遗址的规模从 80 公顷到 1 公顷不 等(Underhill, 2002); (2) 大汶口文化时期(6.0 4.6cal ka BP)不同墓葬中显示出规格和陪葬品数量和质量上的 强烈差异，如位于山东泰安的大汶口M2005墓地的男 性墓主随葬品多达 103 件, 明显高于普通的墓葬(奕丰 实, 2012); (3) 大汶口文化的专业制陶产品中出现了一 些精美陶器, 这些陶器与玉石器、骨角器和象牙雕刻 制品一起，是首领或贵族专用的奢饰品，体现了社会 分层(Underhill, 2002; 森丰实, 2012); (4) 大汶口时期 还可能出现了贵重物品的交换(Liu, 2005).

在安徽含山, 年代为5.6 5.3 cal ka BP的凌家滩遗 址出现了祭坛、积石圈和随葬大量玉器和石器的大型 墓葬, 其中 $07 \mathrm{M} 23$ 出土随葬品 330 件, 包括 200 件玉器, 有长72厘米、重达88公斤的玉猪(栾丰实, 2012). 制作 精美的玉器意味着工艺专业化高度发达，且这些仪式 用的精美玉器出现在少量装备精良的大型墓葬，暗示 领导者的出现及其对仪式权力的控制(Liu和Chen, 2012).

在长江下游环太湖地区, 崧泽文化中晚阶段, 即大 约 $5.5 \mathrm{cal} \mathrm{ka} \mathrm{BP}$ 左右出现了明显的社会复杂化, 表现在 遗址和遗址之间、遗址内部的墓区之间、墓区内的墓 葬之间都出现明显的差异. 主要表现在两个方面: 一是 不同墓区之间出现分化，出现了大墓和小墓分区埋葬， 表明社会基层内部出现了分化; 二是同一墓区不同墓 的随葬品也出现明显差异, 一些墓葬随葬品丰富且规 格较高, 如M91随葬品38件(套), 包括14件玉器(奕丰 实, 2012)

在长江中游的江汉地区，大溪文化期间，即 $5.5 \mathrm{cal}$ $\mathrm{ka} \mathrm{BP}$ 左右, 聚落之间出现明显分化, 出现了城头山大
溪文化阶段的环壕城址; 城头山城址内属于大溪文化 时期 200 多座墓葬之间的差别也开始显现(奕丰实, 2012).

在辽西地区，在红山文化中期，约5.5cal ka BP左 右, 出现大型祭祀建筑群址、大型积石冢群、以及随 葬精美玉器的大墓等(Nelson，1995; 严文明，1999). Nelson(1995)认为牛河梁遗址墓葬能够显示少数社会 精英可以掌控精美手工品的生产.

总之, 越来越多的考古资料显示, 公元前第四千年 纪, 尤其是其后半叶是中国史前社会演进的重要转折 期，中国各主要文化区几乎同步上演着跨越式的发展 (奕丰实, 2012), 产生了明显社会复杂化，且这一演进 事件在整体上近似突变(奕丰实, 2012). 一些学者认为 部分地区甚至进入了酋邦社会(陈淳，2003; Underhill 和Habu，2006). 中国考古和历史学界通常将这种复杂 社会的出现称之为文明起源，并将多地区同时出现社 会复杂化的现象称之为“满天星斗”式文明起源模式 (苏秉琦, 1999).

\section{3 部落间冲突和战争考古证据}

战争证据是社会演进战争理论的一个重要支撑, 但一方面由于一些木制武器不易保存，一些被用作武 器但未加工的石头不易辨别, 导致武器的考古证据往 往严重缺失; 另一方面由于一器多用的现象比较普遍, 使得考古证据存在多解性. 这导致战争在史前社会演 进中的作用被严重低估(LeBlanc, 1999). 因此, 在寻找 战争考古证据时, 需要综合多种证据, 尤其是要考虑不 同证据之间的相互印证性(LeBlanc, 1999; 吴文祥和葛 全胜, 2014). 基于这种原则, 总结和分析中国主要史前 文化区考古证据, 发现在6.0 5.0 cal ka BP阶段, 部落间 存在明显的冲突和战争现象. 这些证据包括象征军权 和王权的武器、具有防御性质的城墙和环壕、非正常 死亡现象等.

\section{1 石钱或玉钱出现}

6.0 5.0 cal ka BP阶段, 最明显的考古证据是随葬 武器开始普遍流行. 在此之前, 武器很少被用来随葬, 而到了这个时期，中原地区的仰韶文化、山东的大汶 口文化、江浙的蓊泽文化和随后的良渚文化、安徽的 薛家岗文化、以及两湖地区的大溪文化则普遍用制作 
精良的石钱或玉钱随葬(钱耀鹏，2000，2009)。原来被 认为缺乏战争证据的辽西地区红山文化区，近来部分 墓葬中也发现了一套完整的带柄端饰的石钱，以及暗 示冲突存在的一具无头人骨(王妍, 2016). 石钱或玉钱 是由石斧演变而来. 石斧起初作为砍伐器使用, 因其在 近身格斗中具备较强的杀伤力，而开始被普遍用于战 争(冈村秀典，1997; 马雨林，2000; 钱耀鹏，2000, 2009). 另外，由于石斧更容易体现威武和雄猛，其功 能一部分逐渐升华为权力和地位的象征, 即钱(冈村秀 典, 1997; 钱耀鹏, 2009). 重要人物死后的陪葬品一般 都用当时社会最重要的物品，因此陪葬的石钱和玉钱 则成为一种重要象征，证明了军事领导者的存在,表明 当时应对部落间的冲突和战争已经成为一个部落最重 要的事务, 同时也间接地证明了当时冲突和战争发生 的普遍性(冈村秀典, 1997; 钱耀鹏, 2009).

\section{2 防御性设施一一城墙和壕沟的修建}

设防性设施是一种利用自然或人为障碍物阻碍他 人进入的聚落的建筑，被认为是能够证明人群之间冲 突最直接的具体物证(Field和Lape, 2010). 考古证据表 明, 中国首次出现城址的时间发生在6.0 5.0 cal ka BP 时段, 而且在中国南北方均有发现. 在南方, 湖南澧县 的城头山城址, 属于大溪-屈家岭文化阶段, 始建于 6.0 cal ka BP左右, 被认为是中国最早的城址, 城头山 城址周围还出现了护城河(湖南省文物考古研究所, 2007), 这属于中国历史时期常见的典型双重防御性设 施, 可能体现了部落间冲突的激烈程度. 在北方, 河南 郑州发现了属于仰韶中晚期(5.3 4.8cal ka BP)的西山 土城以及城壕设施，被认为是在战争背景下产生的双 重防御体系(马世之, 1997); 另外, 西山城址发掘的10 多个坑内还出现了扔弃的人骨，其中一些人骨明显呈 挣扎状, 有的尸骨不全, 身首异处, 进一步证明了当时 人群或部落间的激烈冲突(杨肇清, 1997). 近年来在长 江中下游地区发现了良渚古城，其年代接近 $5.0 \mathrm{cal} \mathrm{ka}$ BP(刘斌等, 2014), 可能属于同一时代的产物. 在其他 主要文化区, 尽管目前尚未发现这一时期的城址, 但是 所有主要文化区都存在防御性的壕沟设施(马雨林, 1998; 钱耀鹏, 2003), 包括以前被认为缺乏冲突和战争 证据的红山文化分布区，如内蒙赤峰地区发现了魏家 窝铺大型环壕遗址(成琮瑭等, 2014).

\section{3 其他证据}

这一阶段中国不同文化区还出土了一些暴力冲突 的考古证据. 江苏北部地区属于大汶口文化的大墩子 遗址出土了插有箭头的大腿骨骼(Underhill, 2002); 上 述河南西山城址发现了人骨乱葬现象(杨肇清，1997); 中原地区庙底沟(6.0 5.3cal ka BP)遗址一期文化垃圾 坑里出现随意摆放的人骨架(陈星灿, 2013); 属于庙底 沟文化阶段的河南临汝阎村遗址出土了 1 件成人瓮棺, 其上绘有一幅精心制作的“鹳鱼石斧图”, 被解释为用 于战争中兵器的图(钱耀鹏, 2009).

总体看来, 尽管史前一些考古证据不易保存, 另一 些考古证据存在多解性，上述中国主要文化区发现的 多种考古证据显示, 在全新世中期6.0 5.0 cal ka BP阶 段, 有关部落间冲突和战争证据出现的频率明显增加, 支持了战争是复杂社会演进主要驱动力的理论(Carneiro, 1970).

\section{4 全新世中期5.5cal ka BP气候事件}

中国是世界上少有几个拥有多种高分辨率古气候 档案的地区之一, 为识别和理解 $5.5 \mathrm{cal} \mathrm{ka} \mathrm{BP}$ 气候事件 提供了丰富的证据. 在青藏高原南部, 平均分辨率为 5 年的天门洞石笋 $\delta^{18} \mathrm{O}$ 记录显示, $5.3 \mathrm{cal} \mathrm{ka} \mathrm{BP}$ 左右发生 了一次明显的弱夏季风事件(Cai等, 2012)(图1g). 在青 藏高原东部, 测年较准确、分辨率较高的红原泥炭单 一植物残体纤维素的 $\delta^{13} \mathrm{C}$ 显示, 5.6 5.2 cal ka BP期间 降水明显减少(Hong等, 2003)(图1d); 其混合植物残体 纤维素的 $\delta^{13} \mathrm{C}$ 显示, 从 $5.5 \mathrm{cal} \mathrm{ka} \mathrm{BP}$ 开始, 夏季风明显减 弱, 降水减少(图2c). 在青海湖, 孢粉记录表明 $5.5 \mathrm{cal} \mathrm{ka}$ $\mathrm{BP}$ 以后, 树木狍粉百分比含量下降, 指示气候变冷 (Shen等, 2005)(图2d); 具有57个年代控制点的青海湖 沉积物粒度、碳酸盐含量、 $\mathrm{TOC}$ 等综合指标显示, 在 5.3cal ka BP左右夏季风减弱(An等, 2012); 祁连山敦 德冰芯 $\delta^{18} \mathrm{O}$ 显示, 6.0 5.0 cal ka BP发生三次明显降温 事件(Thompson等, 1989)(图1c).

在中国北方季风边缘带, 多个湖泊沉积物均显示 $5.5 \mathrm{cal} \mathrm{ka} \mathrm{BP}$ 左右全新世最适宜结束, 如位于夏季风北 部边缘地带的巴彦查干湖的孢粉记录表明, 从 $5.5 \mathrm{cal}$ ka BP开始, 温度降低且降水减少(Jiang等, 2006) (图 $2 \mathrm{e})$; 位于内蒙古中东部的达里湖的湖泊水位重建结果 


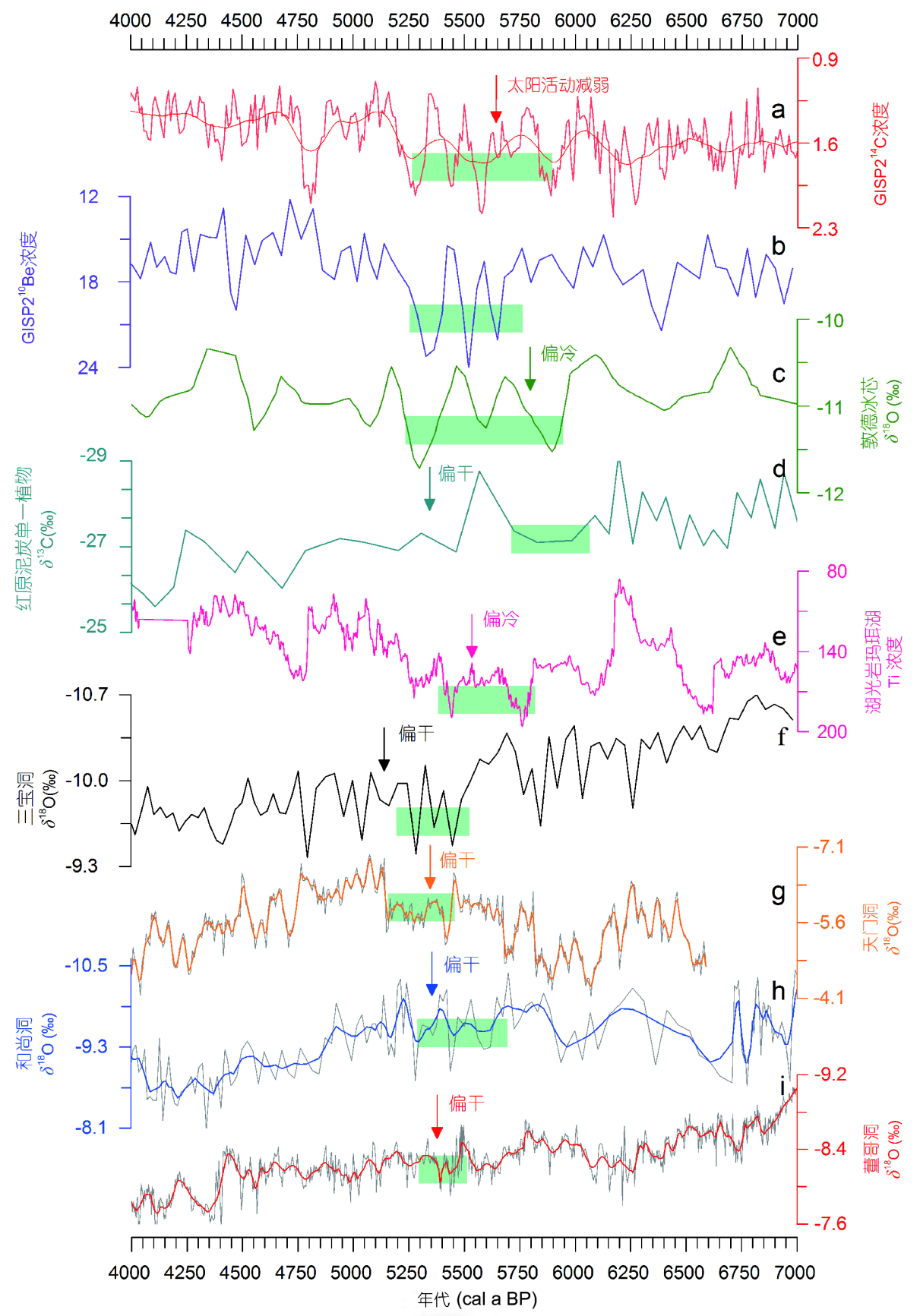

图 1 中国5.5cal ka BP事件典型代用指标记录和太阳活动记录的比较

(a) GISP2 ${ }^{14} \mathrm{C}$ 浓度(Stuiver等, 1998); (b) GISP2 ${ }^{10} \mathrm{Be}$ 浓度(Steinhilber等, 2009); (c) 敦德冰芯 ${ }^{18} \mathrm{O}$ 记录(Thompson等, 1989); (d) 红原泥炭单一植物 $\delta^{13} \mathrm{C}$ 记录(Hong等, 2003); (e) 湖光岩玛珥湖 Ti浓度(Yancheva等, 2007); (f) 三宝洞石笋 $\delta^{18} \mathrm{O}$ 记录(Dong等, 2010); (g) 天门洞石笋 $\delta^{18} \mathrm{O}$ 记录 $(\mathrm{Cai}$ 等, 2012); (h) 和尚洞石笋 $\delta^{18} \mathrm{O}$ 记录( $\mathrm{Hu}$ 等, 2008); (i) 董哥洞石笋 $\delta^{18} \mathrm{O}$ 记录(Wang等, 2005)

显示, 在 $5.5 \mathrm{cal} \mathrm{ka} \mathrm{BP}$ 水位突然下降了 $30 \mathrm{~m}$, 之后再也未 恢复到前期水平(Goldsmith等, 2017).

在黄土高原及其周边地区，山西公海 20 年分辨率
的东亚夏季风降雨量的定量重建结果显示, $5.5 \mathrm{cal} \mathrm{ka}$ BP左右降水量明显开始减少(Chen等, 2015)(图2b). 黄 土高原西部地区 8 年时间分辨率的万象洞石笋 $\delta^{18} \mathrm{O}$ 记 


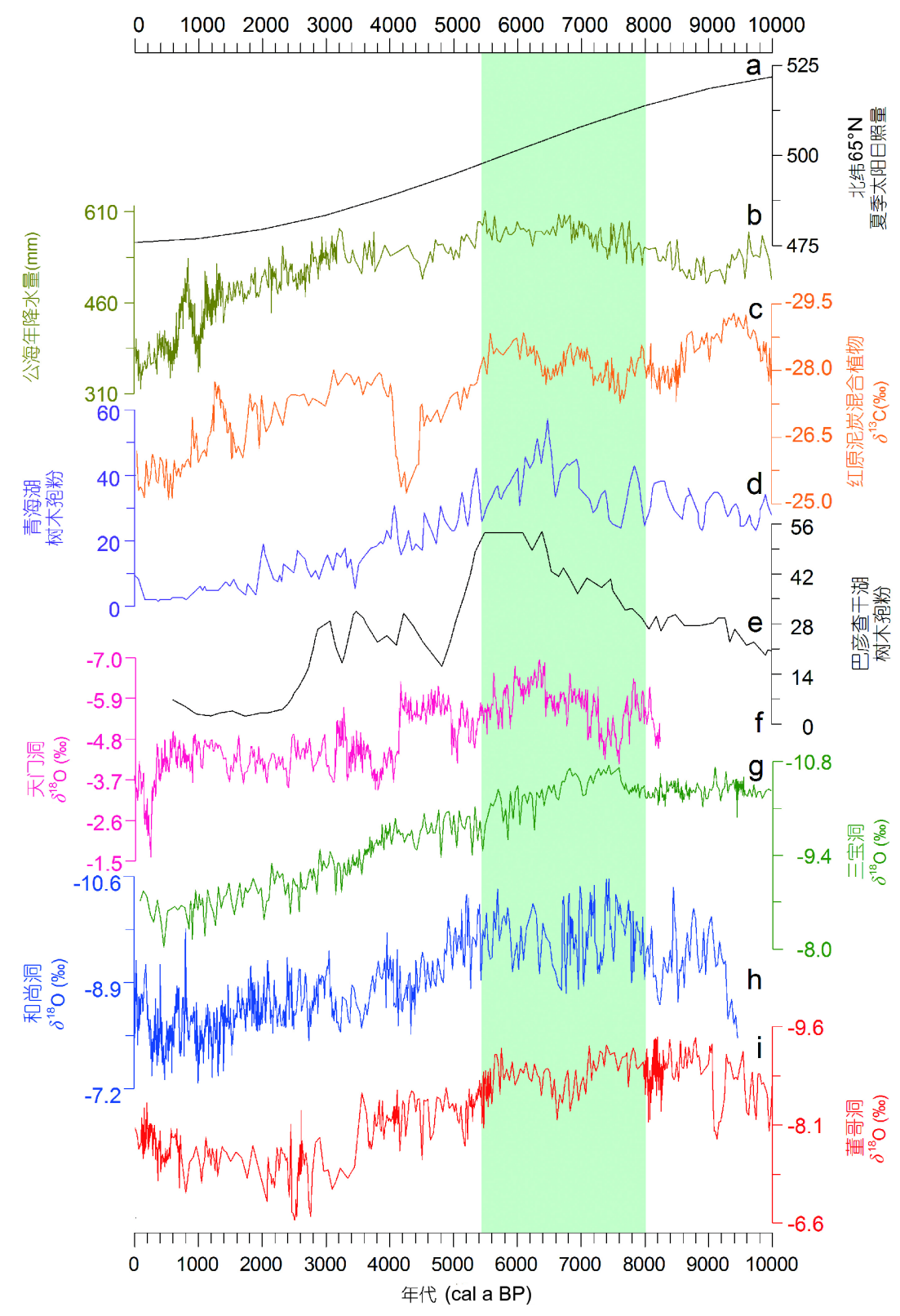

图 2 中国石笋、湖泊记录和太阳辐射量的比较

(a) $65^{\circ} \mathrm{N}$ 夏季太阳日照量(Berger和Loutre, 1991); (b) 公海年降水量重建(Chen等, 2015); (c) 红原泥炭混合植物 $\delta^{13} \mathrm{C}(\mathrm{Hong}$ 等, 2003); (d) 青海湖树 木孢粉百分比(Shen等, 2005); (e) 巴彦查干湖树木孢粉百分比(Jiang等, 2006); (f) 天门洞石笋 $\delta^{18} \mathrm{O}$ 记录(Cai等, 2012); (g) 三宝洞石笋 $\delta^{18} \mathrm{O}$ 记录 (Dong等, 2010); (h) 和尚洞石笋 $\delta^{18} \mathrm{O}$ 记录(Hu等, 2008); (i) 董哥洞石笋 $\delta^{18} \mathrm{O}$ 记录(Dykoski等, 2005). 阴影部分指示全新世大暖期及其5.5cal ka BP 左右的转折

录到5.4cal ka BP左右的极端夏季风减弱事件(白益军 等, 2017). 中原腹地南阳地区4 5年时间分辨率的石笋 $\delta^{18} \mathrm{O}$ 记录到5.8 5.7 cal ka BP和5.3 5.1 cal ka BP期间的 季风减弱事件(任晓辉等, 2006). 在关中盆地, $6.0 \sim 5.0 \mathrm{cal} \mathrm{ka} \mathrm{BP}$ 期间古土壤发育中断，黄土堆积速率
增加(Huang等, 2000).

在东北地区，哈尼泥炭植物残体纤维素 $\delta^{13} \mathrm{C}$ 记录 显示在5.8 5.0 cal ka BP降水明显减少. 附近的金川泥 炭孢粉记录显示, $5.5 \mathrm{cal} \mathrm{ka} \mathrm{BP}$ 温性阔叶林被寒温性针 叶林所代替, 指示气候寒冷(Jiang等, 2008). 大兴安岭 
北部地区霍拉盆地泥炭剖面狍粉记录显示6.0 5.0 cal ka BP阶段气温明显下降(赵超等, 2016). 辽宁省暖和洞 高分辨率的石笋 $\delta^{18} \mathrm{O}$ 显示, 夏季风强度从 $5.5 \mathrm{cal} \mathrm{ka} \mathrm{BP}$ 开始逐渐减弱, 标志着全新世适宜期结束(吴江漟等, 2011).

在长江中游地区, 湖南省龙山县莲花洞(Zhang等, 2013)、清江和尚洞(Hu等, 2008; 图2h)、以及湖北神 农架三宝洞(Dong等, 2010; 图 $2 \mathrm{~g}$ )三个石笋 $\delta^{18} \mathrm{O}$ 均显示 从 $5.5 \mathrm{cal} \mathrm{ka} \mathrm{BP}$ 左右夏季风强度开始减弱.

在中国西南地区, 贵州董哥洞DA石笋氧同位素记 录(图1i)明显记录到5.5cal ka BP前后的季风减弱事件 (Wang等, 2005); 贵州董哥洞另一支石笋(D4) $\delta^{18} \mathrm{O}$ 记录 (图2i)显示5.6 5.2 cal ka BP期间发生显著的季风减弱 事件, 同时标志全新世最适宜期的结束(Dykoski等, 2005). 在华南地区, 广东湛江高分辨率的湖光岩玛珥 湖沉积物钛元素含量(图1e)记录显示, 5.9 5.2 cal ka BP 期间冬季风强度显著增强(Yancheva等, 2007); 而另一 项对该湖泊多指标古气候重建结果表明, 全新世大暖 期在 6.2cal ka BP前后结束(Wang等, 2016).

关于这一阶段气候的定量重建记录较少, 已有的 结果表明当时降温幅度明显. 利用孢粉对岱海湖相沉 积物的定量重建显示，5.8 5.6 cal ka BP间该地区7月 平均温度较前期7.4 6.0 cal ka BP阶段下降了 $4^{\circ} \mathrm{C}$, 比现 在低 $1{ }^{\circ} \mathrm{C}$ (许清海等, 2003); 内蒙古调角海子埋藏古冰 楔现象表明6.0 5.8 cal ka BP年均温较现代低至少 $3^{\circ} \mathrm{C}$ (张兰生等, 1997); 长江下游地区沉积物狍粉重建结果 表明5.5 5.0 cal ka BP期间温度较前期下降了 $1{ }^{\circ} \mathrm{C}$ 左右 (Li等, 2017).

总之，总体看来，中国不同地区大量的测年较准 确, 时间分辨率较高的古气候记录证据表明在全新世 中期6.0 5.0 cal ka BP, 气候发生了明显变化, 主要表 现在两个方面; 一是在此期间发生了多次降温和季风 减弱事件; 二是全新世大暖期结束.

世界其他地区的古气候记录也显示与中国类似的 气候变化特征. 南北半球全新世山地冰川在 $5.3 \mathrm{cal} \mathrm{ka}$ $\mathrm{BP}$ 发生大规模的冰川前进事件, 表明全新世新冰期的 到来(Denton和Karlén, 1973). 来自北大西洋的海洋沉 积物表明, 6.0 5.0 cal ka BP发生了全新世最显著的一 次冰筏事件(图3f), 被称之为“Bond Event 4”(Bond等, 1997). 海洋沉积物有孔虫 $\delta^{13} \mathrm{C}$ 记录(图3i) 表明, 北大西 洋深水环流在 $5.5 \mathrm{cal} \mathrm{ka}$ BP左右明显减弱 $(\mathrm{Oppo}$ 等,
2003). 高质量的格林兰冰芯钾离子、钠离子和钲离子 记录(图3c e e)分别揭示出在6.0 5.0 cal ka BP期间, 西伯 利亚高压增强、冰岛低压减弱、以及西风强度增强 (Mayewski等, 1997). 南极冰芯钻离子(Siple Dome)(图 3b)同样显示出这一时段西风环流增强(Yan等, 2005), 而冰芯氧同位素(Taylor Dome)(图3a)则指示温度下降 (Steig等，2000). 指示热带-亚热带湿地面积变化的格 林兰冰芯记录的甲烷浓度在 $5.2 \mathrm{cal} \mathrm{ka} \mathrm{BP}$ 降至全新世 最低点(Blunier等, 1995; 图3g). 在非洲, 对乞力马扎罗 6 个冰芯的 $\delta^{18} \mathrm{O}$ (图3h)和粉尘含量研究表明, 在 $5.2 \mathrm{cal} \mathrm{ka}$ BP 左右发生一次显著的降温和干旱事件(Thompson 等, 2002).

在较低纬度地区,卡里亚科盆地海洋沉积物 Ti浓 度显示从 $5.5 \mathrm{cal} \mathrm{ka} \mathrm{BP}$ 开始, 降水明显减少, 标志着气候 适宜期结束(Haug等, 2001). 非洲西海岸沉积物陆源物 质含量(图3j)(deMenocal等, 2000b)和海表温度重建(图 $3 \mathrm{k}$ )(deMenocal等, 2000a) 记录显示该地区气候在 $5.5 \mathrm{cal}$ ka BP左右发生突变, 标志着气候最适宜期结束. 这次 气候突变又称之“撒哈拉干旱”事件(deMenocal等, 2000b). 在 $5.5 \mathrm{cal} \mathrm{ka} \mathrm{BP}$ 左右, 沉寂相当一段时期的 $\mathrm{ENSO}$ 气候重新开始活动, 并影响从美国西部到澳大 利亚、新西兰和亚洲的西北部广阔的太平洋地区 (Sandweiss等，1999). Magny和Haas(2004)综合了南、 北半球陆地和海洋的 44 个代用资料, 包括植被、冰 川、高山树线、永冻土、高纬树线、海温、极地冰盖 及热带冰芯, 发现 $5.5 \mathrm{cal} \mathrm{ka} \mathrm{BP}$ 事件具有全球性的特征.

总之, 在测年误差范围内, 目前世界各地的古气候 记录非常明确地显示, 6.0 5.0 cal ka BP期间不仅发生 了全新世最为显著的几次降温事件, 而且这一阶段在 世界许多地区还标志着全新世适宜期的结束(Haug等, 2001; deMenocal等, 2000b)和新冰期的开始(Denton和 Karlén, 1973; Steig等, 1998). 该气候事件还呈现以下 特征: 一是发生区域较广, 可能至少是一次北半球性的 气候事件; 二是发生突然, 气候转变可能在短短十年内 完成(deMenocal等, 2000b).

关于6.0 5.0 cal ka BP气候变化的原因, ${ }^{14} \mathrm{C}$ 记录表 明, 太阳活动在6.0 5.0 cal ka BP期间出现三次明显的 波动(Steinhilber等, 2009; Stuiver等, 1998); 太阳活动减 弱可以直接导致季风强度减弱(Wang等, 2005); 另外, 太阳活动减弱可能导致北大西洋浮冰增加(Bond等, 2001), 北大西洋经向翻转环流(AMOC)变慢(Oppo等, 


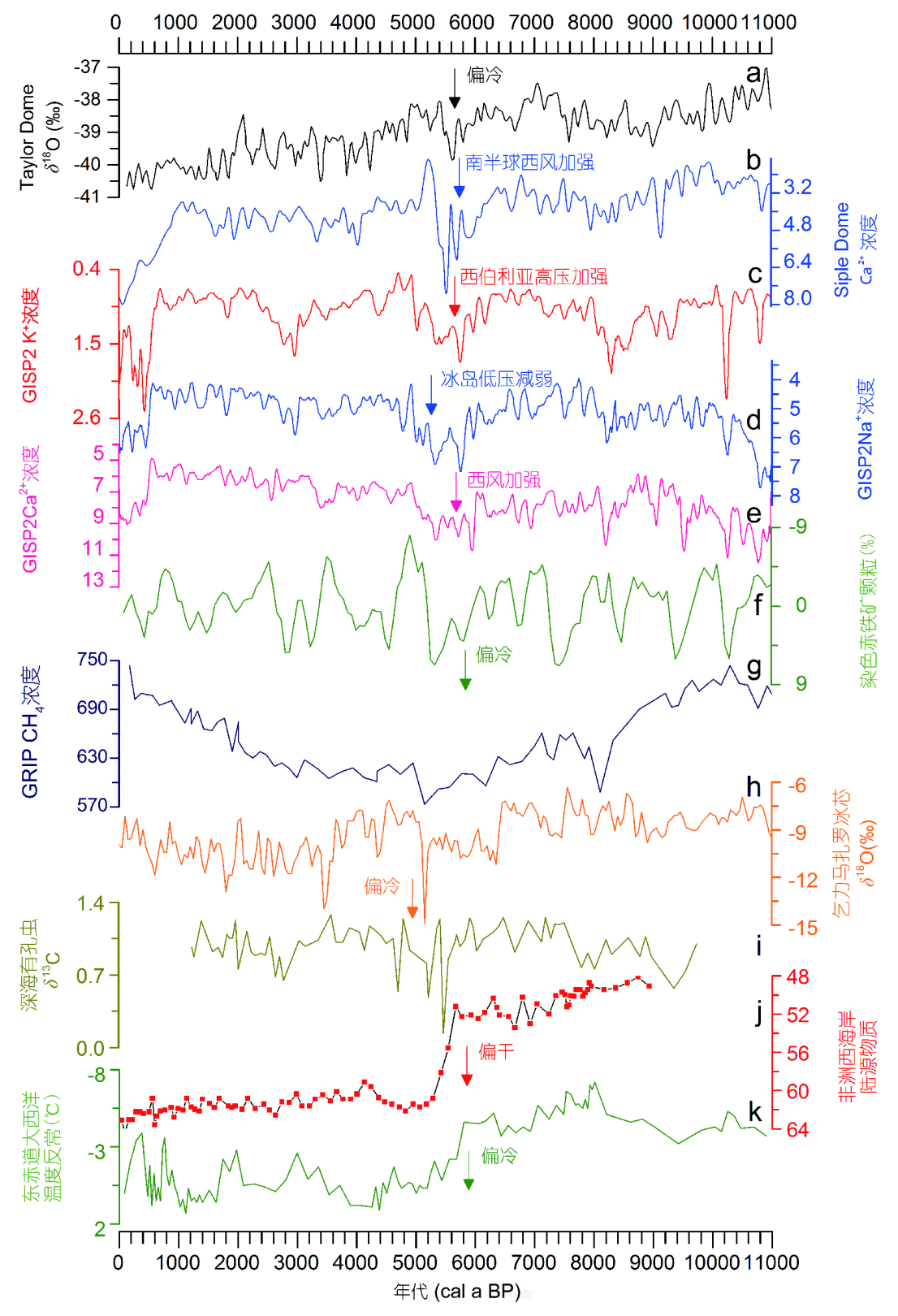

图 3 世界不同地区5.5cal ka BP事件记录

(a) Taylor Dome $\delta^{18}$ O记录(Steig等, 2000); (b) Siple Dome $\mathrm{Ca}^{2+}$ 浓度(Yan等, 2005); (c) GISP2 $\mathrm{K}^{+}$浓度(Mayewski等, 1997); (d) GISP2 Na 浓度 (Mayewski等, 1997); (e) GISP2 Ca ${ }^{2+}$ 浓度(Mayewski等, 1997); (f) 北大西洋染色赤铁矿颗粒(Bond等, 1997); (g) GRIP甲烷浓度(Blunier等, 1995); (h) 乞力马扎罗冰芯 $\delta^{18} \mathrm{O}$ 记录(Thompson等, 2002); (i) 大西洋深海有孔虫 $\delta^{13} \mathrm{C}$ 记录(Oppo 等, 2003); (j) 非洲西海岸陆源物质含量(deMenocal等, 2000b); (k) 非州西海岸海表温度重建(deMenocal等, 2000a)

2003), 而亚洲季风也可能通过大气过程快速响应北大 西洋地区气候变化(Liu等, 2013). 太阳活动减弱可以解 释6.0 5.0 cal ka BP期间的气候异常, 但不能解释 $5.5 \mathrm{cal}$ $\mathrm{ka} \mathrm{BP} 气$ 候发生分水岭式的变化, 而这一变化被认为与 太阳辐射变化有关(deMenocal等, 2000b; 图2a). 气候变
化模拟的结果表明, 气候系统对太阳辐射变化的响应 比较敏感. 而这一时期太阳辐射的变化速率本身就比 较大，再通过一系列大气-海洋-植被反馈机制扩大了 对气候变化的影响, 气候变化一旦超过某种阈值将会 发生气候突变(deMenocal等, 2000b). 因此, 这一阶段 


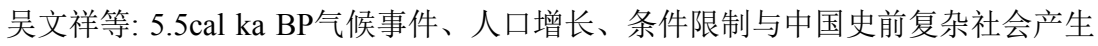

的气候突变可能是由地球轨道驱动与太阳活动触发, 多种因素相互作用的结果(Magny和Haas, 2004).

\section{5 战争形成的原因 $-5.5 \mathrm{cal} \mathrm{ka} \mathrm{BP}$ 人口-资 源失衡}

以上气候重建的结果显示 $6.0 \sim 5.0 \mathrm{cal} \mathrm{ka} \mathrm{BP}$ 为全新 世最适宜期后的一次显著降温阶段，在测年误差范围 内，这一降温期恰好对应于中国多个地区人群间冲突 和战争升级，以及复杂社会产生阶段，暗示三者之间 存在一定的联系. 我们认为三种因素, 即 $5.5 \mathrm{cal} \mathrm{ka} \mathrm{BP}$ 气候事件、人口增长、条件限制共同作用，导致人口资源失衡, 并进而触发人群间的冲突和战争.

\section{1 气候变化的作用}

气候变化的作用主要表现在两个方面：一是直接 影响人类的生活和生产环境; 二是影响区域资源承载 力水平. 在北方，全新世中期人类已经开始广泛种植 粟、㯟作物，这两类作物对水热条件特别是霜冻反应 敏感. 降温将导致积温及无霜期都相应减少，极端冷 事件发生频率增加、幅度增大，这些都将对粟、乘作 物生长产生不利的影响(张东菊等，2016; 方修琦和孙 宁, 1998). 在南方, 5.5 cal ka BP降温期将导致洪涝灾害 事件的增加，进而影响人类居住环境以及水稻生产环 境和产量(Wu和Liu, 2004).

需要指出的是，降温期间极端气候事件的影响不 可忽视. 大量历史文献记录表明，长期气候变化的影 响往往是气候异常阶段短尺度气候事件影响的叠加结 果(De Vries, 1980). 在降温期, 极端寒冷事件发生频率 将会增加. 这些短尺度极端事件将会影响锋面降雨的 强度、持续时间和地理位置(Wu和Liu，2004)，进而导 致一些地区异常降雨事件发生的概率增加，表现为干 旱和洪涝发生的几率可能增加(Zheng和Feng，1986), 从而对人类生活和生产环境，以及作物产量产生不利 的影响. $5.5 \mathrm{cal} \mathrm{ka} \mathrm{BP} 气$ 候事件降温幅度大，降温期间 极端冷事件增加, 将会导致经常性的灾害性事件发生.

\section{2 人口增长的作用}

人口增长在人群间冲突产生过程中起到两种重要 作用; 一是为气候变化影响人口-资源失衡提供必要条 件; 二是形成社会限制条件.

\subsection{1 提供人口-资源失衡的必要条件}

气候变化对人口-资源失衡的影响程度不仅与气 候变化本身特点有关，还与人口接近资源承载力水平 的高低有关. 如果人口数量较少, 低于资源承载力水 平，气候变化对人口-资源失衡的影响程度减轻; 相反, 当人口数量接近土地承载力水平, 幅度较小的气候变 化也能引起人口-资源失衡.

尽管已有研究表明，中国多个地区在全新世适宜 期(8.0 6.0 cal ka BP)期间人口快速增长(Wang等, 2014), 但目前的考古证据尚不能证明当时人口增长接 近至资源承载力水平. 这需要借助人口学理论来认识 人口行为特征并进而了解当时的人口规模. 与其他任 何动物一样, 人类有快速增长人口的能力 (Wood, 1998). 但在人们的印象里往往认为史前人口增长速率 较低. 这种现象的出现其实是由于一段时间人口快速 增长与由密度制约因素和非密度制约因素，如气候变 化、饥荒以及人群间冲突和战争所导致的一段时期人 口迅速减少之间均衡的结果(Boone, 2002).

大量研究表明, 即使工业化之前人口增长速率相 对较低，但在无资源限制的条件下，以指数方式增长 人口将在较短时间内接近资源承载力水平(Cowgill, 1975; Wood, 1998). 关于人口增长速率, 生活在相对边 缘受食环境中的南部非洲的昆人(!Kung)的人口年均 增长率为7\% (Boone, 2002), 热带受食部落一巴拉圭 的Ache 人在与现代人接触前的人口年平均增长率短 时期可以高达 $25 \%$ (Hill和Hurtado, 1996). Richerson等 (2001)研究了人口这种指数方式增长的效果, 他们设 定某个地区人口增长接近土地承载力水平时的最大人 口压力为 $100 \%$, 将人口增长初期的人口压力水平仅为 最大人口压力水平的 $1 \%$ 计算, 人口年平均增长率按 $10 \%$ 计算. 结果表明，仅在 920 年的时间里，人口就增 长至最大人口压力的 $99 \%$. 我们还可以作类似的推测 来认识人口指数增长的效果. Hassan(1979)推测在更 新末期，全球人口为 900 万左右; 较近，Tallavaara等 (2015)的研究表明，在末次冰期末期 1.3 万年左右，欧 洲人口数值为 41 万. 假定 $1.1 \mathrm{cal} \mathrm{ka} \mathrm{BP}$ 左右全球人口为 100 万, 人口增长速率为 $4 \%$, 那么经过 2200 年后, 人口 就增长至97亿; 若年平均人口增长速率按 $10 \%$ 计算, 经 过 1000 年, 100 万的全球人口就增长至 209 亿.

尽管技术进步可以缓解人口-资源压力, 但由于人 
口以几何级数方式增长, 而技术进步带来的资源增量 则以算术级数方式增长, 技术进步只能暂时缓解人口 增长带来的资源压力，在近千年尺度上，无论以哪种 技术水平，在无限制条件下，人口将迅速增长至资源 承载力水平(Wood, 1998; Richerson等, 2001).

在中国, 无论是旱作还是稻作农业, 其起源时间均 超过 1 万年, $8.0 \mathrm{cal} \mathrm{ka} \mathrm{BP}$ 左右已经出现定居农业, $7.0 \sim 6.0 \mathrm{cal} \mathrm{ka} \mathrm{BP}$ 农业明显发生强化(董广辉等, 2016, 2017). 在 8.0 6.0 cal ka BP全新世大暖期，尤其 7.0 6.0 cal ka BP全新世气候最适宜期, 随着定居农耕 社会的建立和农业强化, 人口快速增长, 当时人口增长 数量足以接近至区域资源承载力水平.

\subsection{2 形成条件限制}

若发生人口-资源失衡, 弱势群体最适应的策略是 迁徙至其他有资源可被开发利用的地区. 条件限制是 指能够阻止弱势人群因与其他群体竞争处于劣势时, 而迁徙至其他地区，从而避免被控制而降低自己的社 会地位的环境. Carneiro(1970)提出了两种形式的限制 条件: 一是地理限制, 如某一人群被资源贫㾑的地带, 如沙漠、草原, 或被能够阻碍人群规模性迁徙的地带, 如茂密的森林、山脉、以及湖泊、河流、海洋等面积 较大的水域等包围; 二是社会限制, 即某一人群被周围 人口密集的部落所包围. 在中国主要新石器文化区, 除 北部、西北部和东北部等生态环境脆弱带在 $5.5 \mathrm{cal} \mathrm{ka}$ $\mathrm{BP}$ 气候恶化阶段可能形成一定的地理限制之外，基本 不存在明显的地理限制条件. 但是经过几千年, 尤其是 $8.0 \sim 6.0 \mathrm{cal} \mathrm{ka} \mathrm{BP}$ 介介段全新世气候适宜期的长期增长, 人口增长将会接近土地承载力水平, 足以形成社会限 制条件; 同时, 当时人类已经定居, 这使得迁徙代价增 大，增加了条件限制的力度; 这导致在气候恶化时，人 口不能够通过选择规模性迁徙其他地区来应对资源压 力, 从而导致人口-资源失衡的产生.

\section{6 人口-资源失衡与社会演进}

大量民族学和考古学的研究表明，与其他灵长类 一样，人类普遍倾向于等级制统治下的领导者与普通 成员间的从属关系(Boehm，1999). 这种等级制统治主 要依靠个体身体的物理能力取得. 但随着木制和石制 等致命武器的使用，普通成员惩罚自私和控制欲强的
领导者的代价大大降低，使得通过身体条件达到控制 他人的目的变得不可能(Gintis等，2015). 在人人平等 的道德观指导下，普通成员联合起来、组成强大的道 德共同体，形成旨在防止等级制倾向的社会控制，即 “反支配等级制”(reverse dominance hierarchy). 他们利 用平等化机制(leveling mechanism), 共同监视、反 对、惩罚(包括私下议论、公众與论、指责、嘲弄、 孤立、不服从、罢免、抛弃、处死等)那些滥用权 力、威胁部落成员的自主权和与他人的平等权的人 员, 确保领导者的决策与他们的基本利益大体相符, 最 终保障团体成员都能平等地享受到自然或社会资源、 相应的地位、以及决策的自主权(Boehm, 1999).

因此, 要成为永久性制度化的集权领导, 除了具备 领导才能和技巧之外，最重要的是必须克服平等社会 对可能引起不平等的领导者所实施强大平等化机制的 束缚. 如果领导者能够向追随者证明, 他们会在他的领 导下受益, 社会盛行平等化机制的约束力就会减弱, 普 通成员对领导者行为的监视就有可能放松，领导者的 权力就有机会继续保持甚至扩大，直到合法化和制度 化(Kantner, 2009).

在正常状况下，未来社会或自然变化情景可被预 测，已有的文化机制将会指导如何决策，平等化机制 使得平等主义风气(egalitarian ethos)盛行, 无需集中制 的领导决策; 而在危机时期, 集体或临时性决策将会危 机到群体的生存，而领导集权和集中决策对于集体行 动的成败至关重要(Kantner, 2009), 尤其是在部落之间 的冲突与战争中(Carneiro，1970), 集中决策将会使群 体所有成员都受益. 在这种情况下，平等化机制将会 失效，有抱负或野心的领导者可以克服平等化机制的 限制，进行不平等决策，并可能由此取得财富、地位 甚至权力(Kantner，2009). 如果危机发生的时间较短, 领导权尚未获得合法化和制度化，那么领导将会是临 时的. 危机过后，领导者便失去了作用，社会则又可能 恢复了群龙无首的平等社会状态中(Kantner, 2009). 因 此，领导权仅限于特定的环境和时间段行使. Kantner (2009)提出了产生不平等社会需要的三个因素，即人 口变化、气候环境变化和社会文化环境. 并将人口变 化视为最为关键的因素. 但Kantner(2009)的假说不能 解释包括中国在内的世界多个地区不平等社会为何发 生在 $5.5 \mathrm{cal} \mathrm{ka}$ BP而不是其他时间?

$5.5 \mathrm{cal} \mathrm{ka} \mathrm{BP}$ 气候事件作用于接近资源承载力水平 
的人口密度之上，在社会限制的环境中，导致人口-资 源失衡, 并触发部落间的冲突和战争, 从而为那些渴望 权力和地位的能动者提供了成为领导的机会, 并由此 减轻了平等社会严格的平等化机制的约束，使得能动 者能够成为领导, 导致不平等社会的初现. 但是, 即使 一些能动者暂时获得了领导地位，由于平等化机制的 普遍存在，仍需要一种机制来保障领导地位的维持 (Kantner, 2009). 一些学者强调领导者通过对经济、军 事和意识形态等的控制，来加强自己对社会其他成员 的控制，从而实现社会不平等的制度化和永久性 (Earle，1999). Kantner(2009)则提到了其他因素的作 用，尤其是人口增长引起的梯度压力所导致的部落普 通成员对领导行为的监督力下降. 但这些假说都不能 很好解释中国不平等社会产生的时间. 我们认为 6.0 5.0 cal ka BP冷期, 气候变率增加带来的影响至关 重要. 平均温度的下降将导致极端寒冷事件发生频率 增加，从而导致人口-资源失衡经常性发生，并进而引 起部落间冲突和战争发生的频率增加，为能动者对权 力的追求提供了长久的机会，降低了社会平等机制的 约束，增加了社会对其领导权合法化和制度化的可能 性, 并进而导致永久性制度化不平等社会的维持.

还可能存在一种社会因素，即竞争环境中的群体 选择性压力也会有助于永久性制度化不平等社会的持 续. $5.5 \mathrm{cal} \mathrm{ka} \mathrm{BP}$ 全球性气候事件的影响是广域性的, 最 初将会导致多个部落相互竞争的局面. 在这种情景下, 不平等条件下集权领导的集中决策将比平等条件下的 集体决策更具竞争优势(Kantner, 2009), 那么能动者的 领导地位就会保持. 但是, 一旦危机消除, 持久性不平 等社会制度尚未建立,部落内部的个体之间的竞争力 有可能会超过群体选择性压力，导致社会从不平等向 平等化社会转变. 因此，虽然这种不同团体之间的竞 争有助于不平等社会的维持，但同样依赖于外部的竞 争环境. 从这个角度看, 冷期中的极端气候事件的增 加是维持不平等社会持续存在的一个关键因素.

\section{7 结论}

本文从能动性理论角度, 对 $5.5 \mathrm{cal} \mathrm{ka} \mathrm{BP}$ 左右复杂 社会的产生提出了一种新的可供检验的假说. 我们的 假说在以下三个方面与前人认识有所不同. 首先，与 前人往往单独强调气候变化所引起资源压力不同, 我
们则强调了气候变化、人口增长、以及条件限制三种 因素共同作用引起区域性的人口-资源失衡; 第二, 我 们强调了气候变率的作用, 认为6.0 5.5 cal ka BP冷期 阶段极端降温事件的增加，引起的人口-资源持续经常 性失衡, 并进而触发较长时段的冲突和战争, 减轻了平 等化机制的制约，为一些能动者提供了成为永久性制 度化领导的机会, 并最终促使 $5.5 \mathrm{cal} \mathrm{ka} \mathrm{BP}$ 左右中国永 久性制度化不平等社会的最终形成; 第三, 我们从人类 能动性的角度建立了气候变化与复杂社会演进之间成 因链, 避免了简单的环境决定论, 并有助于理解最初社 会复杂化产生的真正动因.

与其他的假说相比, 我们的假说不仅能够解释中 国复杂社会最初产生并得以持续的过程和动因, 而且 还能够解释其他假说所不能解释的两个现象: 一是为 何中国复杂社会开始产生于 $5.5 \mathrm{cal} \mathrm{ka} \mathrm{BP}$ 前后而不是 其他时间; 二是为何不同地区人群在大致同一时间进 入复杂社会.

\section{参考文献}

白益军, 张平中, 高涛, 余仁哲, 周鹏超, 程海. 2017. 亚洲夏季风 $5400 \mathrm{a}$ BP极端减弱事件与文化演变. 中国科学: 地球科学, 47 : $554-566$

陈淳. 2003. 酋邦的考古学观察. 见: 陈淳, 著. 考古学的理论与研究. 上海: 学林出版社. 592-606

陈星灿. 2013. 庙底沟时代: 早期中国文明的第一缕曙光. 中国文物 报, 第005版

成琮塘, 塔拉, 曹建恩, 熊增珑. 2014. 内蒙古赤峰魏家窝铺新石器时 代遗址的发现与认识. 文物, 11: 47-52

董广辉, 张山佳, 杨谊时, 陈建徽, 陈发虎. 2016. 中国北方新石器时 代农业强化及对环境的影响. 科学通报, 61: 2913-2925

董广辉, 刘峰文, 陈发虎. 2017. 不同空间尺度影响古代社会演化的 环境和技术因素探讨. 中国科学: 地球科学, 47: 1383-1394 冈村秀典. 1997. 中国新石器时代的战争. 华夏考古, 3: 100-112 方修琦, 孙宁. 1998. 降温事件: $4.3 \mathrm{ka}$ BP 岱海老虎山文化中断的可 能原因. 人文地理, 13: 71-76

湖南省文物考古研究所. 2007. 禮县城头山-新石器时代遗址发掘报 告. 北京: 文物出版社

李新伟. 2016. “最初的中国”之考古学认定. 考古, 3: 86-92

刘斌, 王宁远, 郑云飞, 陈旭高, 周文林, 问凯凯, 陈明辉, 祁自力, 芦 希彦, 陈全和. 2014. 2006 2013年良渚古城考古的主要收获. 东 南文化, 2: 31-38

奕丰实. 2012. 试论仰韶时代中期的社会分层. 东方考古, 9: 44-56 
马世之. 1997. 郑州西山仰韶文化城址浅析. 中州学刊, 4: 135-139

马雨林. 1998. 中国史前防御设施纵谈. 中原文物, 1: 30-33

马雨林. 2000. 谈谈史前战争的有关问题. 见: 西安半坡博物馆, 编.

史前研究. 西安: 三秦出版社. 535-541

钱耀鹏. 2000. 史前武器及其军事学意义考察. 文博, 6: 21-29

钱耀鹏. 2003. 中国史前防御设施的社会意义考察. 华夏考古, 3: 4148

钱耀鹏. 2009. 中国古代斧钱制度的初步研究. 考古学报, 1: 1-34

任晓辉, 董进国, 陈昌海. 2006. 中全新世河南南阳石笋记录的百年

季风干旱事件. 中国岩溶, 25: 269-273

苏秉琦. 1999. 中国文明起源新探. 北京: 生活. 读书·新知三联书店

王妍. 2016. 红山文化首现军权标志. 辽宁日报, 第T05版

王震中. 2014. 中心聚落形态, 原始宗邑与酋邦社会的整合研究. 中 原文化研究, 2: 5-14

吴江漟, 汪永进, 董进国. 2011. 全新世东亚夏季风演化的辽宁暖和 洞石笋 $\delta^{18} \mathrm{O}$ 记录. 第四纪研究, 31: 990-998

吴文祥, 葛全胜. 2014. 4.5 4.0ka BP气候变化、人口增长、条件限 制与黄河中下游地区龙山酋邦社会产生. 第四纪研究, 34: 253265

吴文祥, 刘东生. 2002. 5500a BP气候事件在三大文明古国古文明和 古文化演化中的作用. 地学前缘, 9: 155-162

许清海, 肖举乐, 中村俊夫, 阳小兰, 杨振京, 梁文栋, 井内美郎, 杨素 叶. 2003. 孢粉资料定量重建全新世以来岱海盆地的古气候. 海 洋地质与第四纪地质, 23: 99-108

杨肇清. 1997. 试论郑州西山仰韶文化晚期古城址的性质. 华夏考古, 1: $55-59$

严文明. 1999. 文明起源研究的回顾与思考. 文物, 10: 27-34

张东菊, 董广辉, 王辉, 任晓燕, 哈比布, 强明瑞, 陈发虎. 2016. 史前 人类向青藏高原扩散的历史过程和可能驱动机制. 中国科学: 地 球科学, 46: 1007-1023

张兰生, 方修琦, 任国玉, 索秀芬. 1997. 我国北方农牧交错带的环境 演变. 地学前缘, 4: 127-136

赵超, 李小强, 周新郢, 赵克良, 杨青. 2016. 北大兴安岭地区全新世 植被演替及气候响应. 中国科学: 地球科学, 46: 870-880

An Z, Colman S M, Zhou W, Li X, Brown E T, Jull A J T, Cai Y, Huang Y, Lu X, Chang H, Song Y, Sun Y, Xu H, Liu W, Jin Z, Liu X, Cheng P, Liu Y, Ai L, Li X, Liu X, Yan L, Shi Z, Wang X, Wu F, Qiang X, Dong J, Lu F, Xu X. 2012. Interplay between the Westerlies and Asian monsoon recorded in Lake Qinghai sediments since 32 ka. Sci Rep, 2: 619

Berger A, Loutre M F. 1991. Insolation values for the climate of the last 10 million years. Quat Sci Rev, 10: 297-317

Blunier T, Chappellaz J, Schwander J, Stauffer B, Raynaud D. 1995. Variations in atmospheric methane concentration during the Holocene epoch. Nature, 374: 46-49

Boehm C. 1999. Hierarchy in the Forest: The Evolution of Egalitarian
Behavior. Cambridge: Harvard University Press

Bond G, Kromer B, Beer J, Muscheler R, Evans M N, Showers W, Hoffmann S, Lotti-Bond R, Hajdas I, Bonani G. 2001. Persistent solar influence on north Atlantic climate during the Holocene. Science, 294: 2130-2136

Bond G, Showers W, Cheseby M, Lotti R, Almasi P, Demenocal P, Priore P, Cullen H, Hajdas I, Bonani G. 1997. A pervasive millennial-scale cycle in north Atlantic Holocene and glacial climates. Science, 278: 1257-1266

Boone J L. 2002. Subsistence strategies and early human population history: An evolutionary ecological perspective. World Archaeol, 34: 6-25

Brooks N. 2006. Cultural responses to aridity in the Middle Holocene and increased social complexity. Quat Int, 151: 29-49

Cai Y, Zhang H, Cheng H, An Z, Lawrence Edwards R, Wang X, Tan L, Liang F, Wang J, Kelly M. 2012. The Holocene Indian monsoon variability over the southern Tibetan Plateau and its teleconnections. Earth Planet Sci Lett, 335-336: 135-144

Carneiro R L. 1970. A Theory of the origin of the state: Traditional theories of state origins are considered and rejected in favor of a new ecological hypothesis. Science, 169: 733-738

Chen F, Xu Q, Chen J, Birks H J B, Liu J, Zhang S, Jin L, An C, Telford R J, Cao X, Wang Z, Zhang X, Selvaraj K, Lu H, Li Y, Zheng Z, Wang H, Zhou A, Dong G, Zhang J, Huang X, Bloemendal J, Rao Z. 2015. East Asian summer monsoon precipitation variability since the last deglaciation. Sci Rep, 5: 11186

Clark J E, Blake M. 1994. The power of prestige: competitive generosity and the emergence of rank societies in Lowland Mesoamerica. In: Brumfiel E, Fox J W, eds. Factional Competition and Political Development in the New World. Cambridge: Cambridge University Press. 17-30

Cowgill G L. 1975. On causes and consequences of ancient and modern population changes. Am Anthropol, 77: 505-525

De Vries J. 1980. Measuring the impact of climate on history: The search for appropriate methodologies. In: Rotberg R I, Rabb T K, eds. Climate and History. Studies in Interdisciplinary History. Princeton: Princeton University Press. 19-50

deMenocal P, Ortiz J, Guilderson T, Sarnthein M. 2000a. Coherent high- and low-latitude climate variability during the Holocene warm period. Science, 288: 2198-2202

deMenocal P, Ortiz J, Guilderson T, Adkins J, Sarnthein M, Baker L, Yarusinsky M. 2000b. Abrupt onset and termination of the African Humid Period: Rapid climate responses to gradual insolation forcing. Quat Sci Rev, 19: 347-361

Denton G H, Karlén W. 1973. Holocene climatic variations-Their pattern and possible cause. Quat Res, 3: 155-205 
Dong J, Wang Y, Cheng H, Hardt B, Edwards R L, Kong X, Wu J, Chen S, Liu D, Jiang X. 2010. A high-resolution stalagmite record of the Holocene East Asian monsoon from Mt Shennongjia, central China. Holocene, 20: 257-264

Dykoski C A, Edwards R L, Cheng H, Yuan D, Cai Y, Zhang M, Lin Y, Qing J, An Z, Revenaugh J. 2005. A high-resolution, absolute-dated Holocene and deglacial Asian monsoon record from Dongge Cave, China. Earth Planet Sci Lett, 233: 71-86

Earle T. 1999. The evolution of chiefdoms. In: Earle T, ed. Chiefdoms: Power, Economy, and Ideology. Cambridge: Cambridge University Press. 1-15

Field J S, Lape P V. 2010. Paleoclimates and the emergence of fortifications in the tropical Pacific islands. J Anthropol Archaeol, 29: $113-124$

Gintis H, van Schaik C, Boehm C. 2015. Zoon Politikon: The evolutionary origins of human political systems. Curr Anthropol, 56: $327-353$

Goldsmith Y, Broecker W S, Xu H, Polissar P J, deMenocal P B, Porat N, Lan J, Cheng P, Zhou W, An Z. 2017. Northward extent of East Asian monsoon covaries with intensity on orbital and millennial timescales. Proc Natl Acad Sci USA, 114: 1817-1821

Hassan F A. 1979. Demography and archaeology. Annu Rev Anthropol, 8: $137-160$

Haug G H, Hughen K A, Sigman D M, Peterson L C, Röhl U. 2001. Southward migration of the intertropical convergence zone through the Holocene. Science, 293: 1304-1308

Hayden B. 1995. Pathways to power: Principles for creating socioeconomic inequalities. In: Price $\mathrm{T}$ D, Feinman $\mathrm{G}$ M, eds. Foundations of Social Inequality. New York: Plenum. 15-86

Hayden B. 2001. Richman, Poorman, Beggarman, Chief: The dynamics of social inequality. In: Feinman G, Price T D, eds. Archaeology at the Millenium: A Sourcebook. New York: Kluwer Academic Publishers. $213-268$

Hill K, Hurtado M. 1996. Ache Life History: The Ecology and Demography of a Foraging People. Chicago: Aldine de Gruyter

Hong Y T, Hong B, Lin Q H, Zhu Y X, Shibata Y, Hirota M, Uchida M, Leng X T, Jiang H B, Xu H, Wang H, Yi L. 2003. Correlation between Indian Ocean summer monsoon and north Atlantic climate during the Holocene. Earth Planet Sci Lett, 211: 371-380

Hu C, Henderson G M, Huang J, Xie S, Sun Y, Johnson K R. 2008. Quantification of Holocene Asian monsoon rainfall from spatially separated cave records. Earth Planet Sci Lett, 266: 221-232

Huang C C, Zhou J, Pang J, Han Y, Hou C. 2000. A regional aridity phase and its possible cultural impact during the Holocene Megathermal in the Guanzhong Basin, China. Holocene, 10: 135142
Jiang W, Guo Z, Sun X, Wu H, Chu G, Yuan B, Hatté C, Guiot J. 2006. Reconstruction of climate and vegetation changes of Lake Bayanchagan (Inner Mongolia): Holocene variability of the East Asian monsoon. Quat Res, 65: 411-420

Jiang W, Leroy S A G, Ogle N, Chu G, Wang L, Liu J. 2008. Natural and anthropogenic forest fires recorded in the Holocene pollen record from a Jinchuan peat bog, northeastern China. Palaeogeogr Palaeoclimatol Palaeoecol, 261: 47-57

Kantner J. 2009. Identifying the pathways to permanent leadership. In: Eerkens J W, Vaughn K J, Kantner J, eds. The Evolution of Leadership: Transdtions in Decision Making from Small-scale to Middle-range Societies. Santa Fe, NM: School for Advanced Research Press. 249-281

Kennett D J, Kennett J P. 2006. Early state formation in Southern Mesopotamia: Sea Levels, shorelines, and climate change. J Island Coastal Archaeol, 1: 67-99

Kintigh K W, Altschul J H, Beaudry M C, Drennan R D, Kinzig A P, Kohler T A, Limp W F, Maschner H D G, Michener W K, Pauketat T R, Peregrine P, Sabloff J A, Wilkinson T J, Wright H T, Zeder M A. 2014. Grand challenges for archaeology. Proc Natl Acad Sci USA, 111: 879-880

Kǜper R, Kröpelin S. 2006. Climate-controlled Holocene occupation in the Sahara: Motor of Africa's evolution. Science, 313: 803-807

LeBlanc S A. 1999. Prehistoric Warfare in the American Southwest. Salt Lake City: University of Utah Press

Li J, Dodson J, Yan H, Wang W, Innes J B, Zong Y, Zhang X, Xu Q, Ni J, Lu F. 2017. Quantitative Holocene climatic reconstructions for the lower Yangtze region of China. Clim Dyn, 1-13. doi: 10.1002/ 2016JD026333.

Liu L. 2005. The Chinese Neolithic: Trajectories to Early States. Oxford City: Cambridge University Press

Liu L, Chen X. 2012. The Archaeology of China: From the Late Paleolithic to the Early Bronze Age. Oxford City: Cambridge University Press

Liu Y H, Henderson G M, Hu C Y, Mason A J, Charnley N, Johnson K R, Xie S C. 2013. Links between the East Asian monsoon and north Atlantic climate during the 8200 year event. Nat Geosci, 6: 117-120

Magny M, Haas J N. 2004. A major widespread climatic change around 5300 cal. yr BP at the time of the Alpine Iceman. J Quat Sci, 19: 423-430

Marcus J. 2008. The archaeological evidence for social evolution. Annu Rev Anthropol, 37: 251-266

Mattison S M, Smith E A, Shenk M K, Cochrane E E. 2016. The evolution of inequality. Evol Anthropol, 25: 184-199

Mayewski P A, Meeker L D, Twickler M S, Whitlow S, Yang Q, Lyons W B, Prentice M. 1997. Major features and forcing of high-latitude 
northern hemisphere atmospheric circulation using a 110000-yearlong glaciochemical series. J Geophys Res, 102: 26345-26366

McGuire R H. 1983. Breaking down cultural complexity: Inequality and heterogeneity. J Archaeol Meth Th, 6: 91-142

Nelson S M. 1995. The Archaeology of Northeast China: Beyond the Great Wall. London: Routledge

Oppo D W, McManus J F, Cullen J L. 2003. Palaeo-oceanography: Deepwater variability in the Holocene epoch. Nature, 422: 277-277

Richerson P J, Boyd R, Bettinger R L. 2001. Was agriculture impossible during the Pleistocene but mandatory during the Holocene? A climate change hypothesis. Am Antiquity, 66: 387-411

Sandweiss D H, Maasch K A, Anderson D G. 1999. Climate and culture: Transitions in the Mid-Holocene. Science, 283: 499-500

Shen J, Liu X, Wang S, Ryo M. 2005. Palaeoclimatic changes in the Qinghai Lake area during the last 18000 years. Quat Int, 136: 131140

Steig E J, Brook E J, White J W C, Sucher C M, Bender M L, Lehman S J, Morse D L, Waddington E D, Clow G D. 1998. Synchronous climate changes in Antarctica and the north Atlantic. Science, 282: $92-95$

Steig E J, Morse D L, Waddington E D, Stuiver M, Grootes P M, Mayewski P A, Twickler M S, Whitlow S I. 2000. Wisconsinan and holocene climate history from an ice core at taylor dome, western ross embayment, antarctica. Geogr Ann Ser A-Phys Geogr, 82: 213235

Steinhilber F, Beer J, Fröhlich C. 2009. Total solar irradiance during the Holocene. Geophys Res Lett, 36: 308

Stuiver M, Reimer P J, Braziunas T F. 1998. High-precision radiocarbon age calibration for terrestrial and marine samples. Radiocarbon, 40: 1127-1151

Tallavaara M, Luoto M, Korhonen N, Järvinen H, Seppä H. 2015. Human population dynamics in Europe over the Last Glacial Maximum. Proc Natl Acad Sci USA, 112: 8232-8237

Thompson L G, Mosley-Thompson E, Davis M E, Bolzan J F, Dai J, Klein L, Yao T, Wu X, Xie Z, Gundestrup N. 1989. Holocene-Late Pleistocene climatic ice core records from Qinghai-Tibetan Plateau. Science, 246: 474-477

Thompson L G, Mosley-Thompson E, Davis M E, Henderson K A, Brecher H H, Zagorodnov V S, Mashiotta T A, Lin P N, Mikhalenko V N, Hardy D R, Beer J. 2002. Kilimanjaro ice core records: Evidence of Holocene climate change in tropical Africa. Science, 298: 589-593

Underhill A P. 2002. Craft Production and Social Change in Northern
China. New York: Kluwer Academic/Plenum Publishers

Underhill A, Habu J. 2006. Early sedentary communities in East Asia: Economic and sociopolitical organization at the local and regional levels. In: Stark M. ed. An Archaeology of Asia. Malden: Blackwell Publishers. 121-148

Vaughn K J, Eerkens J W, Kantner J. 2009. The Evolution of Leadership: Transitions in Decision Making From Small-scale to Middle-range Societies. Santa Fe: School for Advanced Research Press

Wang C, Lu H, Zhang J, Gu Z, He K. 2014. Prehistoric demographic fluctuations in China inferred from radiocarbon data and their linkage with climate change over the past 50000 years. Quat Sci Rev, 98: 45-59

Wang X, Chu G, Sheng M, Zhang S, Li J, Chen Y, Tang L, Su Y, Pei J, Yang Z. 2016. Millennial-scale Asian summer monsoon variations in South China since the last deglaciation. Earth Planet Sci Lett, 451: $22-30$

Wang Y, Cheng H, Edwards R L, He Y, Kong X, An Z, Wu J, Kelly M J, Dykoski C A, Li X. 2005. The Holocene Asian monsoon: Links to solar changes and north Atlantic climate. Science, 308: 854-857

Wiessner P. 2002. The vines of complexity: Egalitarian structures and the institutionalization of inequality among the Enga. Curr Anthropol, 43: 233-269

Wood J W. 1998. A theory of preindustrial population dynamics demography, economy, and Well-Being in Malthusian Systems. Curr Anthropol, 39: 99-135

Wu W, Liu T. 2004. Possible role of the "Holocene Event 3" on the collapse of Neolithic Cultures around the Central Plain of China. Quat Int, 117: 153-166

Yancheva G, Nowaczyk N R, Mingram J, Dulski P, Schettler G, Negendank J F W, Liu J, Sigman D M, Peterson L C, Haug G H. 2007. Influence of the intertropical convergence zone on the East Asian monsoon. Nature, 445: 74-77

Yan Y, Mayewski P A, Kang S, Meyerson E. 2005. An ice-core proxy for Antarctic circumpolar zonal wind intensity. Ann Glaciol, 41: $121-130$

Zhang H L, Yu K F, Zhao J X, Feng Y X, Lin Y S, Zhou W, Liu G H. 2013. East Asian Summer Monsoon variations in the past $12.5 \mathrm{ka}$ : High-resolution $\delta^{18} \mathrm{O}$ record from a precisely dated aragonite stalagmite in central China. J Asian Earth Sci, 73: 162-175

Zheng S, Feng L. 1986. Historical evidence on climatic instability above normal in cool periods in China. Sci China Ser-B, 29: 441448 